\title{
ANÁLISE DAS METAS DO PROGRAMA NACIONAL DE HABITAÇÃO RURAL (PNHR) NO CONTEXTO NACIONAL
}

\author{
Julie Rossato Fagundes ${ }^{1}$ \\ Liziane Campigotto ${ }^{2}$ \\ Paulo Zonta ${ }^{3}$ \\ Sirlei Favero Cetolin ${ }^{4}$
}

\section{RESUMO}

Este artigo tem como objetivo analisar o desenvolvimento do Programa Nacional de Habitação Rural (PNHR), quanto ao cumprimento das metas estipuladas pelo Ministério das Cidades para todas as regiões do país. Também visa analisar, de forma qualitativa, os indicadores regionais que levaram, ou não, o Programa a alcançar seus objetivos. Mesmo em andamento e faltando mais de um ano para encerrar o Programa, é possível verificar o resultado parcial e o número de contratos efetivados até o segundo semestre de 2013. O PNHR faz parte da política social implantada no governo atual para facilitar o acesso à moradia, oportunizando habitação rural para os agricultores e familiares em condições socioeconômicas vulneráveis. O estudo apresenta uma síntese dos dados alcançados pelo Programa em cada região do Brasil. Esta análise pode proporcionar sugestões de melhorias no Programa e/ou novos direcionamentos específicos dentro da política pública da habitação, visando suprir eventuais necessidades.

Palavras-chave: Gestão Social. Políticas Públicas. Programa Nacional de Habitação Rural.

\section{ABSTRACT}

This paper aims to evaluate the development of the National Rural Housing (PNHR), for the targets set by the Ministry of Cities for each region of the country and analyze, qualitatively, the regional leading indicators, or not, the Program achieve their goals. Even in progress and missing more than a year to finish the program, you can verify that the partial result and the number of contracts effected by the second half of 2013 by the Program. The PNHR part of social policy implemented in the current government to faci-

\footnotetext{
${ }^{1}$ Mestranda em Administração da Universidade do Oeste de Santa Catarina (Unoesc), Chapecó/SC. jurfagundes@hotmail.com

${ }^{2}$ Mestranda em Administração da Unoesc, Chapecó/SC. Icamp@unochapeco.edu.br

${ }_{3}^{3}$ Mestrando em Administração da Unoesc, Chapecó/SC. paulozonta@uol.com.br

${ }^{4}$ Doutora em Serviço Social, Mestre em Gestão de Políticas Públicas. Professora e pesquisadora da Unoesc. sirleicetolin@gmail.com
} 
litate access to housing housing providing opportunities for farmers and rural families in vulnerable socioeconomic conditions. The study provides an overview of the data achieved by the program in each region of Brazil. This analysis can provide suggestions for improvements in the program and/or specific new directions within the public housing policy, in order to meet any needs.

Keywords: Social Management. Public Policy. National Rural Housing.

\section{INTRODUÇÃO}

O setor habitacional do Brasil há muito tempo é afetado pela falta de moradias, tanto em áreas urbanas como em áreas rurais (ROVER; MUNARINI, 2010). Embora a moradia seja constitucionalmente resguardada, muitas famílias ainda carecem de um local digno e com condições básicas de habitabilidade para viver. $\mathrm{O}$ acesso à moradia é um fator de melhoria da qualidade de vida das famílias agricultoras e pode causar um impacto positivo sobre as dinâmicas de desenvolvimento rural que se venha a propor.

Em 2009, o Governo Federal iniciou o Programa Nacional de Habitação Rural (PNHR), com objetivo de reduzir o histórico déficit habitacional das áreas rurais. O PNHR faz parte de uma política social implantada no governo atual para facilitar o acesso à moradia aos agricultores familiares em condições socioeconômicas vulneráveis. É importante mencionar que, até então, o setor rural era agraciado com políticas econômicas voltadas ao incentivo da lavoura e reformas de suas instalações (estábulos, chiqueiros, etc.), através do Programa Nacional de Fortalecimento da Agricultura Familiar (PRONAF), entretanto, muitas vezes, as dependências da propriedade rural eram melhores que a própria moradia da família.

Diante do exposto, o objetivo da pesquisa é verificar o desenvolvimento do PNHR quanto às metas estipuladas pelo Ministério das Cidades para cada região do país e analisar, de forma qualitativa, os indicadores regionais que levaram ou não o Programa a alcançar seus objetivos. Mesmo em andamento e faltando mais de um ano para encerrar o Programa, é possível verificar o resultado parcial e o número de contratos efetivados até o segundo semestre de 2013.

A relevância do trabalho está em analisar uma política social do governo, seus números e seus resultados até a presente data. O trabalho faz uma síntese dos dados alcançados pelo Programa em cada região do Brasil. Esta análise pode proporcionar sugestões de melhorias no Programa ou de novos direcionamentos específicos dentro da política pública da habitação, visando suprir eventuais necessidades.

Partindo do objetivo da pesquisa, o trabalho está organizado da seguinte forma: (ii) fundamentação teórica no intuito de embasar o objetivo proposto; (iii) metodologia utilizada para a realização do estudo; (iv) apresentação e análise dos dados a partir dos procedimentos metodológicos definidos; (v) considerações finais; (vi) referências. 


\section{POLÍTICAS PÚBLICAS E GESTÃO SOCIAL}

Segundo Albuquerque (2006), o Brasil é um país marcado pela desigualdade e por uma cultura do privilégio e do favor que predomina sobre a consciência dos direitos. É nesse contexto que o empenho de setores democráticos da sociedade civil, especialmente os movimentos sociais, vêm, desde as lutas contra a ditadura militar e a conquista de uma Constituição de 1988, convergindo para a construção de políticas públicas inclusivas, que buscam garantir direitos universais e o direito de a sociedade civil exercer um controle público sobre elas.

De acordo com Sampaio (2012), as lutas da sociedade civil que antecederam e caracterizaram o período da redemocratização deram visibilidade às grandes demandas sociais, que se transformaram posteriormente em políticas públicas. Movimentos sociais, associações, entidades de classe e categorias profissionais construíram uma pauta de reivindicações que incluía direitos civis, políticos e sociais, como a melhoria das condições de vida, salário, educação e saúde. Esses atores construíram a agenda de mudanças que desaguou na elaboração da nova Constituição Federal, promulgada em 1988, inaugurando, assim, uma nova ordem democrática.

Souza (2006) ressalta que não existe uma única, nem melhor, definição sobre o que seja política pública. Além disso, salienta que a definição mais conhecida continua sendo a de Laswell, ou seja, decisões e análises sobre política pública implicam responder às seguintes questões: quem ganha o quê, por que e que diferença faz.

Para Souza (2006), resumidamente, política pública pode ser entendida como o campo do conhecimento que busca, ao mesmo tempo, "colocar o governo em ação" e/ou analisar essa ação (variável independente) e, quando necessário, propor mudanças no rumo ou curso dessas ações (variável dependente).

Ainda de acordo com Souza (2006), entre as diversas definições e modelos sobre políticas públicas, podem-se extrair e sintetizar seus elementos principais:

1) A política pública permite distinguir entre o que o governo pretende fazer e o que, de fato, faz.

2) A política pública envolve vários atores e níveis de decisão, embora seja materializada através dos governos, e não necessariamente se restringe a participantes formais, já que os informais são também importantes.

3) A política pública é abrangente e não se limita a leis e a regras.

4) A política pública é uma ação intencional, com objetivos a serem alcançados.

5) A política pública, embora tenha impactos no curto prazo, é uma política de longo prazo.

6) A política pública envolve processos subsequentes após sua decisão e proposição, ou seja, implica também implementação, execução e avaliação.

Carvalho (1999) relaciona gestão social à gestão das ações públicas, viabilizadas a partir das necessidades e demandas apontadas pela população, através de projetos, programas e políticas públicas que assegurem respostas efetivas à realidade das "maiorias". A autora dá ênfase ao protagonismo da sociedade civil, no sentido da identificação das necessidades e demandas, assim como da proposição e do controle de ações e políticas 
a serem assumidas pelo Estado.

Maia (2005) aponta a gestão social como um tema recente, que se introduz na sociedade brasileira na década de 1990, em meio à tensão entre dois processos que marcam a realidade contemporânea: a globalização da economia e a regulação social tardia, através das conquistas de cidadania, do Estado democrático de direitos e dos desafios da participação da sociedade civil. Por se tratar de um tema de estudos recente, é possível observar uma variedade de abordagens que procuram explicar o seu conceito e a sua aplicação.

Dowbor (1999) remete a gestão social à transformação da sociedade, em que a atividade econômica passa a ser o meio e o bem-estar social o fim do desenvolvimento. Para isso, indica a necessidade da construção de um novo paradigma organizacional, a partir da redefinição da relação entre o político, o econômico e o social. Propõe a articulação entre empresários, administradores públicos, políticos, organizações não governamentais, sindicatos, pesquisadores, movimentos sociais, universidades, representantes comunitários, entre outros. França Filho (2007) ainda considera que a gestão social refere-se a algo que se elabora num espaço público, seja ele estatal ou societário, ou mesmo, na confluência entre eles, representada na articulação entre Estado e sociedade.

Singer (1999), por sua vez, afirma que a gestão social diz respeito às ações que intervêm nas diferentes áreas da vida social para a satisfação das necessidades da população, que se colocam desde a questão do "abandono de crianças" até a questão da crise do trabalho. Sua perspectiva é a de que a gestão social seja viabilizada através de políticas e práticas sociais articuladas e articuladoras das diversas demandas e organizações populares, universidades, entidades não governamentais e governos.

Esse emaranhado de conceitos remete a um único propósito: ao gerir o que é público ou que é bem comum de todos, proporcionar à sociedade o acesso às condições mínimas de vida, seja na área educacional, trabalhista, de moradia, de saúde, entre outras. O que se observa é a inserção das empresas privadas no desenvolvimento de políticas sociais, buscando colaborar privativamente com a sociedade no desenvolvimento do bem-estar comum, uma vez que o Estado, como responsável por tais políticas, não atende integralmente à tal necessidade.

\subsection{Políticas de habitação no Brasil}

O tema moradia ganha importância e relevância a partir da Declaração Universal dos Direitos Humanos $(2013)^{5}$, que, em seu artigo 25, cita: “[...] todos têm o direito a um padrão de vida adequado, à saúde e ao bem-estar de sua família, incluindo alimentação, vestimenta, moradia [...]".

A atual Constituição da República Federativa do Brasil', em seu Capítulo II, artigo 6o, define que "São direitos sociais a educação, a saúde, a alimentação, o trabalho, a moradia, o lazer, a segurança, a previdência social, a proteção à maternidade e à infância, a assistência aos desamparados, na forma desta Constituição", redação dada pela Emenda

\footnotetext{
${ }^{5}$ Carta redigida em 10 de dezembro de 1948 pela Organização das Nações Unidas.

${ }^{6}$ Constituição da República Federativa do Brasil (2013), promulgada em 5 de novembro de 1988.
} 
Constitucional no 64, de 04.02.10. Já em seu Art. 23, parágrafo IX, a Constituição Brasileira define que: "É competência comum da União, dos Estados, do Distrito Federal e dos Municípios: promover programas de construção de moradias e a melhoria das condições habitacionais e de saneamento básico".

No Governo militar de 1964/1985, houve a criação do Banco Nacional da Habitação (BNH), do Serviço Federal de Habitação e Urbanismo (SERFHAU) e do Sistema Financeiro de Habitação (SFH). Foram criados também o Fundo de Garantia por Tempo de Serviço (FGTS) e o Sistema Brasileiro de Poupança e Empréstimo (SBPE).

Para Raichelis (2000), a democratização das políticas sociais no Brasil tem origem no quadro político dos anos 1980, quando emergem com vigor as lutas contra a ditadura militar e os esforços pela construção democrática do Estado e da sociedade civil.

O Governo de Itamar Franco, entre 1992 e 1994, criou a Secretaria Nacional de Habitação, do extinto Ministério do Bem-Estar Social. O programa estimulava os municípios a criar fundos e conselhos municipais de habitação. Já no Governo de Fernando Henrique Cardoso, esse programa foi acentuado com a criação dos conselhos estaduais de habitação (LANNOY, 2006) e, em seu segundo Governo, foi criada a Secretaria Especial de Desenvolvimento Urbano (SEDU). No mesmo ano, surgiu o programa Minha Casa, oferecendo às famílias com renda inferior a seis salários mínimos um programa de arrendamento residencial com futura opção de compra.

No ano de 2003, o então Presidente Luís Inácio Lula da Silva, criou o Ministério das Cidades, que, por sua vez, iniciou o Sistema Nacional de Habitação e criou os Conselhos Nacionais, Estaduais e Municipais de Desenvolvimento Urbano. Criou também os Fundos de Moradia nas três esferas governamentais, a Agência Nacional de Regulamentação e Financiamento Habitacional, os agentes promotores e financeiros públicos e privados (MINISTÉRIO DAS CIDADES, 2013).

A habitação rural começou a ser discutida com mais ênfase na Constituição Federal de 1988, que, em seu Art. 187, define:

A política agrícola será planejada e executada na forma da lei, com a participação efetiva do setor de produção, envolvendo produtores e trabalhadores rurais, bem como os setores de comercialização, de armazenamento e de transportes, levando em conta, especialmente, no item VIII, a habitação para o trabalhador rural.

A Lei 8.171/91 de Política Agrícola faz referência à questão da política de habitação rural, no capítulo XX: Da Habitação Rural, em que dispõe os seguintes artigos:

Art. 87. É criada a política de habitação rural, cabendo à União destinar recursos financeiros para a construção e/ou recuperação da habitação rural. [...] Art . 89. O poder público estabelecerá incentivos fiscais para a empresa rural ou para o produtor rural, nos casos em que sejam aplicados recursos próprios na habitação para o produtor rural.

Em 2009, o Governo do Presidente Luis Inácio Lula da Silva aprovou Programa Nacional de Habitação Rural (PNHR), com o objetivo de reduzir o déficit rural, facilitando o acesso à moradia para os agricultores familiares em condições socioeconômicas mais vulneráveis. 
Souza (2002) define que uma política pública estabelece normas de interesse social em prol do bem coletivo. Uma política deve, a partir de diretrizes gerais, prever os princípios, metas, objetivos, competências institucionais, os conselhos, os recursos e estabelecer as ações e os instrumentos para implantação. Pereira (1996) define políticas públicas como "[...] linha de ação coletiva que concretiza direitos sociais declarados e garantidos em lei [...]". Para Raichelis (2008), "é mediante as políticas públicas que são distribuídos ou redistribuídos bens e serviços sociais em resposta às demandas da sociedade e, por isso, o direito que as fundamenta é um direito coletivo e não individual".

O controle social sugere a participação da sociedade nas decisões políticas, viabilizando a participação da sociedade civil organizada na formulação e na revisão das regras que conduzem as negociações e arbitragens sobre os interesses comuns, segundo Raichelis (2008).

A moradia é uma necessidade humana decorrente da natureza social e é o lugar que garante a existência e a segurança humana. Para Lannoy (2006), essa condição de subsistência faz da falta de moradia um grave problema no Brasil.

Lannoy (2006) relaciona o conceito de déficit habitacional ao "déficit por reposição de estoque", ou seja, àquelas moradias que já não apresentam mais condições de habitação. Já o "déficit por incremento de estoque" é entendido como os locais improvisados, que não são originalmente destinados à moradia, além de locais com ônus excessivo de aluguel.

\subsection{A habitação no Brasil}

O perfil das condições de habitação no país, segundo informações do Censo Demográfico de 2000, mostra um predomínio de habitações do tipo casa, com cerca de 3,8 moradores por domicílio. Um total de 16,9 milhões de habitações - onde residem cerca de 70 milhões de pessoas - possui destino inadequado de dejetos, enquanto que cerca de 5,6 milhões de domicílios na área urbana e 4,3 milhões na área rural possuem abastecimento de água inadequado. Em relação às condições ambientais do domicílio, que possuem estreita relação com condições de saúde, há uma marcante desigualdade regional, principalmente no que diz respeito ao tipo de esgotamento sanitário e existência de banheiro, características que apresentam quadro mais precário nas regiões Norte e Nordeste. Esse quadro aponta para a presença marcante de morbimortalidade por Doenças Relacionadas a um Saneamento Ambiental Inadequado - DRSAI no país (COSTA et al., 2002; PONTES et al., 2002), que se expressam fortemente através das internações e dos óbitos por diarreias infecciosas, principalmente nas já citadas regiões do país.

\section{PROGRAMA NACIONAL DE HABITAÇÃO RURAL - PNHR}

O Plano Nacional de Habitação, previsto pela Lei 11.124/05, foi elaborado entre agosto de 2007 e dezembro de 2008. Tem como perspectiva o planejamento de longo prazo pelo Governo Federal e pretende conferir estabilidade para a política habitacional, protegendo-a de oscilações políticas e orçamentárias, responsáveis pela fragmentação da intervenção do poder público no setor.

40 | COLÓQUIO - Revista do Desenvolvimento Regional - Faccat - Taquara/RS - v. 10, n. 2, jul./dez. 2013 
Resultado dessa política, o Programa Nacional de Habitação Rural (PNHR), também conhecido como "Minha Casa Minha Vida Rural", foi criado em 2009. Integrante do Programa Minha Casa, Minha Vida (PMCMV), objetiva a produção ou reforma de imóveis aos agricultores familiares e trabalhadores rurais, por intermédio de operações de repasse de recursos do Orçamento Geral da União ou de financiamento habitacional com recursos do Fundo de Garantia do Tempo de Serviço (FGTS), reduzindo o déficit habitacional rural.

Entre os principais atores envolvidos no processo político do PNHR, destacam-se, por parte do Estado: o Ministério da Fazenda (MF), responsável pelo repasse dos recursos financeiros destinados à aplicação do programa; o Ministério das Cidades (MC), que é o gestor da aplicação dos recursos do FGTS e OGU, e ainda é responsável por estabelecer os parâmetros operacionais do programa, bem como acompanhar e avaliar os resultados obtidos na aplicação dos recursos; a Caixa Econômica Federal (CAIXA) e o Banco do Brasil S/A, que são os agentes operadores e financeiros, responsáveis diretos pela operacionalização do programa. Citam-se ainda as Entidades Organizadoras (EO), que são as pessoas jurídicas sem fins lucrativos que contratam ou formam parcerias com a Caixa ou o Banco do Brasil S/A, para viabilizar e execução do empreendimento. Como exemplos, podem-se citar as cooperativas e associações criadas com o fim específico de dar viabilidade a execução do programa.

A participação no Programa está condicionada aos critérios estabelecidos em três grupos: GI, GII e GIII.

No GI, a principal finalidade é a concessão de subsídios, com recursos do Orçamento Geral da União (OGU), aos agricultores familiares, organizados sob a forma coletiva, por meio de uma Entidade Organizadora, para produção da unidade habitacional em área rural, sob a modalidade de aquisição de material para a construção, conclusão ou reforma/ampliação da UH. O público-alvo são pessoas físicas, agricultores familiares ${ }^{7}$, com renda familiar bruta anual de até 15 mil reais, que comprovem enquadramento no PRONAF Grupo "B", "C", "V" e "A - Beneficiários do PNCF", ou o trabalhador rural com renda familiar bruta anual de até 15 mil reais.

Em relação ao subsídio concedido ao beneficiário do Gl, o recurso é de até 25 mil reais, destinado à construção da unidade habitacional, através de pagamento do material de construção e mão-de-obra, ou de até 15 mil reais, destinado à conclusão, reforma ou ampliação da unidade habitacional, e também deve ser utilizado para pagamento do material de construção e mão-de-obra. O prazo de construção previsto após a assinatura do contrato é entre 4 e 12 meses.

Após doze meses da assinatura do contrato, $4 \%$ do valor do subsídio da edificação é devolvido pelo beneficiário ao OGU, a título de contrapartida do beneficiário, em 4 (quatro) parcelas anuais, sem juros e sem atualização monetária.

Nos grupos GII e GIII, a principal finalidade é a concessão de financiamento habitacional (no âmbito do SFH) e subsídios (lastreados em recursos do FGTS e do OGU) a pessoas físicas - agricultor familiar e trabalhador rural - organizados por uma Entidade

\footnotetext{
7 Enquadram-se como agricultores familiares os pescadores artesanais, extrativistas, silvícolas, aquicultores, maricultores, piscicultores, ribeirinhos, comunidade quilombolas, povos indígenas e demais comunidades tradicionais.
} 
Organizadora, para a produção da unidade habitacional em área rural, sob a modalidade de aquisição de material para a construção, conclusão ou reforma/ampliação da UH.

O público-alvo desses grupos são pessoas físicas, agricultores familiares, com renda familiar bruta anual de $\mathrm{R} \$ 15.000,01$ até $\mathrm{R} \$$ 60.000,00, que comprovem seu enquadramento no PRONAF mediante apresentação da Declaração de Aptidão ao PRONAF - DAP, em qualquer dos grupos B, C, D ou V, e o trabalhador rural com renda familiar bruta anual de $R \$ 15.000,01$ até $R \$ 60.000,00$.

\begin{tabular}{|l|r|r|}
\hline \multicolumn{1}{|c|}{ Região } & Déficit Habitacional Rural & \multicolumn{1}{c|}{$\%$} \\
\hline Norte & 107.058 & 11,68 \\
\hline Nordeste & 641.107 & 69,95 \\
\hline Sudeste & 76.888 & 8,39 \\
\hline Sul & 61.813 & 6,74 \\
\hline Centro-Oeste & 29.612 & 3,23 \\
\hline Brasil & 916.478 & 100,00 \\
\hline
\end{tabular}

Quadro 1: Déficit Habitacional Rural no Brasil Fonte: IBGE, 2008.

Para a implementação do Programa, foram definidos participantes responsáveis em diferentes setores, como o Ministério das Cidades, que é o órgão gestor da aplicação; o Ministério da Fazenda, responsável pelo repasse dos recursos; a Caixa Econômica Federal, responsável pela gestão operacional e agente financiador, juntamente com o Banco do Brasil; algumas entidades organizadoras, como o poder público, cooperativas, associações e sindicatos.

De acordo com a Superintendente Nacional de Habitação Rural da Caixa Econômica Federal, Noemi Lemes, a criação de um programa específico para a zona rural tornou-se necessária devido às especificidades da área rural em relação à urbana, entre elas: 1) logística diferente, já que a construção de casas na área urbana é feita a partir de grupamentos, enquanto na zona rural costumam ser individualizadas; 2) as distâncias e as formas de chegada do material precisam ser consideradas, já que em algumas regiões, como no Norte, o acesso a determinados locais somente é possível por meio de embarcações; 3) a construção das casas obedece a especificidades culturais e climáticas, havendo diferenças nas habitações para comunidades indígenas e quilombolas, por exemplo; 4) a renda considerada tem apuração diferente, já que na região urbana, considera-se a renda mensal, enquanto na área rural a apuração é feita por safra; 5) na zona rural, o terreno em que será construída a habitação nem sempre tem a sua documentação regular.

Existem condições mínimas que os beneficiários devem possuir para participar do PNHR, quais sejam:

- Não ter sido beneficiário, a qualquer época, de subvenções habitacionais lastreadas nos recursos orçamentários da União ou de descontos habitacionais concedidos com recursos do Fundo de Garantia do Tempo de Serviço (FGTS). 
- Não ser proprietário, cessionário ou promitente comprador de imóvel residencial em qualquer localidade do território nacional.

- Não possuir financiamento imobiliário ativo, no âmbito do SFH, em qualquer localidade do território nacional.

- Não possuir pendências no CADIN ou junto à Receita Federal.

- Não possuir área superior a 4 (quatro) módulos fiscais.

- A idade do beneficiário mais velho, somada ao prazo de financiamento, não pode ultrapassar 80 anos, 5 meses e 29 dias para os Grupos 2 e 3.

- Ser indicado pela entidade organizadora.

- Ter capacidade civil.

- Ser brasileiro nato ou naturalizado.

- Apresentar a Declaração de Aptidão ao Pronaf (DAP) emitida nos últimos 3 anos até a data de apresentação da proposta/projeto de intervenção da Entidade Organizadora.

\section{METODOLOGIA}

A pesquisa tratada neste artigo é caracterizada como uma pesquisa descritiva, com abordagem concomitantemente qualitativa e quantitativa.

[...] a pesquisa descritiva procura descobrir, com a precisão possível, a frequência com que um fenômeno ocorre, sua relação e conexão, com os outros, sua natureza e características, correlacionando fatos ou fenômenos sem manipulá-lo (CERVO; BERVIAN, 1996, p. 49).

Vieira (2002) e Malhotra (2001) concordam com tal afirmativa, destacando que a pesquisa descritiva objetiva conhecer e interpretar a realidade, por meio da observação, da descrição, da classificação e da interpretação de fenômenos, sem nela interferir para modificá-la.

Complementando, Vieira (2002) destaca ainda que as pesquisas descritivas podem se interessar pelas relações entre variáveis e, dessa forma, aproximar-se das pesquisas experimentais. A pesquisa descritiva expõe as características de determinada população ou fenômeno, mas não tem o compromisso de explicar os fenômenos que descreve, embora sirva de base para tal explicação.

Foram levantados dados quantitativos sobre o programa em nível de país, junto à Caixa Econômica Federal e ao Banco do Brasil (Entidades Organizadoras do Programa) e ao Ministério das Cidades, o que tornou possível compreender os resultados atingidos pelo Programa desde sua implementação.

Seguindo ensinamentos de Richardson (1989), a pesquisa quantitativa caracteriza-se pelo emprego da quantificação, tanto nas modalidades de coleta de informações quanto no seu tratamento através de técnicas estatísticas, desde as mais simples até as mais complexas.

Qualitativamente, foram aplicados questionários estruturados, enviados via e-mail, por meio de contato por meio digital com a Assistente Social do Ministério das Cidades, em Brasília, e com a Superintendente do Programa Nacional de Habitação Rural junto à Caixa Econômica Federal, também em Brasília. Os questionários foram compostos por 
perguntas abertas cujas respostas discursivas foram avaliadas pela metodologia da análise de conteúdo.

A pesquisa qualitativa, segundo Neves (1996), constitui-se de um conjunto de técnicas de interpretação que busca a descrição e a decodificação de fenômenos e sistemas em seus diversos componentes. Segundo Godoy (1995), ao implementar uma pesquisa qualitativa, o pesquisador envolve-se diretamente com a situação estudada na busca por dados que descrevam pessoas, lugares e processos e que permitam o entendimento da situação estudada pela visão que têm os sujeitos envolvidos.

Por fim, foi realizada uma revisão bibliográfica sobre a conceituação de políticas públicas e gestão social; um histórico da política de habitação no Brasil, a legislação, desenvolvimento e resultados alcançados pelo Programa Nacional de Habitação Rural (PNHR) no país.

\section{ANÁLISE DOS DADOS}

Conforme dados obtidos com a aplicação do questionário e com a pesquisa bibliográfica, o Programa Nacional de Habitação Rural (PNHR) foi lançado através da Portaria Interministerial 326 de 31/agosto/2009 (Publicado no DOU em 2/setembro/2009). As metas estão definidas na subseção V, Art. 10, parágrafo $1^{\circ}$ : “A distribuição entre as Regiões foi efetuada de acordo com a estimativa do 'déficit' habitacional, para as áreas rurais, considerando os dados da Pesquisa Nacional por Amostra de Domicílios - PNAD, da Fundação Instituto Brasileiro de Geografia e Estatística - IBGE, referentes ao ano de 2008".

A meta inicial do PNHR, em 2009, foi de 60 mil unidades. Em 2011, esse número foi alterado para 120 mil contratações, com o objetivo de ser alcançado até o final do ano de 2014 , conforme quadro abaixo.

\begin{tabular}{|c|c|c|}
\hline Região & Metal Inicial & Meta atual \\
\hline Nordeste & 39.402 & 78.804 \\
\hline Norte & 7.803 & 15.606 \\
\hline Sul & 4.551 & 9.102 \\
\hline Sudeste & 5.509 & 11.018 \\
\hline Centro-Oeste & 2.735 & 5.470 \\
\hline Total & 60.000 & 120.000 \\
\hline
\end{tabular}

Quadro 2: Metas do PNHR

Fonte: Caixa Econômica Federal (2013).

Os dados atualizados das contratações realizadas até o $2^{\circ}$ semestre de 2013 foram coletados junto à Caixa Econômica Federal e estão dispostos no Quadro 3. 


\begin{tabular}{|l|r|r|r|r|r|r|r|r|r|r|}
\hline \multicolumn{1}{|c|}{ Região } & $\begin{array}{c}\mathbf{2 0 0 9} \\
\text { S2 }\end{array}$ & $\begin{array}{c}\mathbf{2 0 1 0} \\
\text { S1 }\end{array}$ & $\begin{array}{c}\mathbf{2 0 1 0} \\
\text { S2 }\end{array}$ & $\begin{array}{c}\mathbf{2 0 1 1} \\
\text { S1 }\end{array}$ & $\begin{array}{c}\mathbf{2 0 1 1} \\
\text { S2 }\end{array}$ & $\begin{array}{c}\mathbf{2 0 1 2} \\
\text { S1 }\end{array}$ & $\begin{array}{c}\mathbf{2 0 1 2} \\
\text { S2 }\end{array}$ & $\begin{array}{c}\mathbf{2 0 1 3} \\
\text { S1 }\end{array}$ & $\begin{array}{c}\mathbf{2 0 1 3} \\
\text { S2 }\end{array}$ & Total \\
\hline Centro- Oeste & 0 & 75 & 125 & 323 & 33 & 194 & 2.162 & 462 & 230 & 3.604 \\
\hline Nordeste & 0 & 940 & 706 & 602 & 1.141 & 2.005 & 9.120 & 5.407 & 3.567 & 23.488 \\
\hline Norte & 0 & 0 & 295 & 75 & 1.440 & 498 & 4.285 & 2.525 & 1.831 & 10.949 \\
\hline Sudeste & 25 & 500 & 1.347 & 638 & 920 & 2.231 & 3.814 & 2.778 & 1.682 & 13.935 \\
\hline Sul & 75 & 527 & 2.736 & 2.316 & 4.231 & 4.988 & 12.420 & 5.276 & 2.214 & 34.783 \\
\hline Total & 100 & 2.042 & 5.209 & 3.954 & 7.765 & 9.916 & 31.801 & 16.448 & 9.524 & 86.759 \\
\hline
\end{tabular}

Quadro 3: Contratações desde o início do Programa até metade do $2^{\circ}$ semestre de 2013 Fonte: Caixa Econômica Federal (2013).

O Quadro 4 mostra o desempenho de cada região do Brasil quanto à efetividade do PNHR até o segundo semestre de 2013.

\begin{tabular}{|l|r|r|r|r|r|}
\hline \multicolumn{1}{|c|}{ Região } & \multicolumn{1}{c|}{$\begin{array}{c}\text { Meta } \\
\text { Inicial }\end{array}$} & \multicolumn{1}{c|}{$\begin{array}{c}\text { Meta } \\
\text { Atual }\end{array}$} & $\begin{array}{c}\text { Contratos até } \\
\text { 2013 S 2 }\end{array}$ & $\begin{array}{c}\text { Percentual } \\
\text { atingido/ } \\
\text { Meta inicial }\end{array}$ & $\begin{array}{c}\text { Percentual } \\
\text { atingido/ } \\
\text { Meta atual }\end{array}$ \\
\hline Centro-Oeste & 2.735 & 5.470 & 3.604 & $131,78 \%$ & $65,89 \%$ \\
\hline Nordeste & 39.402 & 78.804 & 23.488 & $59,60 \%$ & $29,80 \%$ \\
\hline Norte & 7.803 & 15.606 & 10.949 & $140,32 \%$ & $70,16 \%$ \\
\hline Sudeste & 5.509 & 11.018 & 13.935 & $252,94 \%$ & $126,47 \%$ \\
\hline Sul & 4.551 & 9.102 & 34.783 & $764,30 \%$ & $382,15 \%$ \\
\hline Total & 60.000 & 120.000 & 86.759 & $144,60 \%$ & $72,30 \%$ \\
\hline
\end{tabular}

Quadro 4: Comparativo de metas/realizado até o $2^{\circ}$ semestre de 2013

Fonte: Autores (2013).

O Quadro 4 ilustra que o Ministério das Cidades dobrou a meta inicial, a qual já foi superada em $44,60 \%$. Levando-se em consideração a meta inicial, apenas a Região Nordeste não alcançou os objetivos propostos, enquanto as demais regiões ultrapassaram o objetivo.

Já para a meta atual, existe uma defasagem para as regiões Centro-Oeste, Norte e Nordeste, enquanto as regiões Sul e Sudeste já suplantaram as metas atuais definidas. Observa-se que a região Sul mais que triplicou a meta atual.

Segundo a Superintendente da Caixa Econômica Federal, em Brasília, várias são as razões para a região Sul ter um melhor desempenho no PNHR. Dentre essas, as principais são: a renda familiar, a organização dos Movimentos Sociais, a formação de Cooperativas e a estrutura organizacional que os próprios imigrantes traziam de seus países.

Para a assistente social do Ministério das Cidades em Brasília, a região Sul "tem um forte histórico de organizações sociais, até mesmo na habitação". Dentre essas instituições estão as Cooperativas, sindicatos e associações que, dentro do PNHR, são reconhecidas como Entidades Organizadoras. 
Apesar de ter o maior déficit habitacional rural do país, de quase $70 \%$ (dados do IBGE de 2008), a região Nordeste foi a que menos contratou proporcionalmente as metas estipuladas. As regiões Norte e Nordeste possuem um nível de pobreza maior, observando-se que muitas famílias não possuem título de posse. Outro fator é a dificuldade logística, especialmente na região Norte do país, onde muitas áreas ficam alagadas durante boa parte do ano.

De acordo com Noemi Lemes, superintendente da Caixa Econômica Federal, o outro motivo é que os valores no início do programa eram muito baixos, o que exigia uma contrapartida maior da entidade organizadora ou da própria família para construir a casa, dificultando a contratação das famílias rurais na região Nordeste.

Outra questão é a estrutura fundiária, que é deficiente em muitas regiões. Apesar de esse problema ser generalizado no país, as regiões Norte e Nordeste têm problemas maiores, fruto da ocupação territorial inicial com forte concentração de terra e da falta de regularização em áreas onde houve distribuição ou fragmentação das propriedades, segundo Cláudia Lúcia Soares de Oliveira, Assistente Social (MINISTÉRIO DAS CIDADES, 2013). Ela enfatiza que o Programa Nacional de Habitação Rural (PNHR) permite a inclusão de beneficiários posseiros, mas há documentos difíceis de conseguir. Em um cenário de organização social ainda frágil, as populações do Norte e do Nordeste do país ficam prejudicadas ao tentarem obter recursos junto ao Programa.

Os dados levantados na aplicação dos questionários corroboram com os dados analisados na bibliografia encontrada, confirmando as diferenças regionais no Brasil.

\section{CONSIDERAÇÕES FINAIS}

Este trabalho teve como objetivo verificar o desenvolvimento do PNHR quanto às metas estipuladas pelo Ministério das Cidades para cada região do país. Além disso, procurou analisar, de forma qualitativa, os indicadores regionais que levaram ou não o Programa a alcançar seus objetivos.

A análise dos dados mostra que a constituição e o funcionamento atual do PNHR atende à demanda das regiões mais ricas e de maior renda familiar, ou seja, as regiões Sul e Sudeste, mas não atende, em sua plenitude, as outras regiões do Brasil, como o Norte e o Nordeste, que possuem maior déficit habitacional. O próprio Ministério das Cidades observou isso no início do programa, aumentando os valores iniciais contratados pelos agricultores familiares.

Para Rover e Munarini (2010), o programa foi constituído a partir de demanda das organizações dos agricultores familiares. Essas organizações foram determinantes para o alcance dos resultados e dos recursos mobilizados no Sul do Brasil, principalmente quando comparados com outras regiões.

A participação de organizações sociais, como Entidades Organizadoras, foi responsável por promover o PNHR, organizando a agricultura familiar para aderir ao programa.

O resultado da análise demonstrou a necessidade de readequação de critérios do Programa, visando atender às regiões menos favorecidas do país, como a regularização 
fundiária nas regiões Norte e Nordeste, e a uma maior participação das entidades governamentais quanto ao subsídio, ou uma possível ampliação do prazo para pagamento do subsídio nas regiões mais carentes.

Apesar dos resultados positivos do Programa nas demais regiões, os dados do IBGE demonstram que o déficit habitacional rural na região Nordeste, que é de $70 \%$, ainda necessita de uma política social regional, com critérios diferentes daquela implantada no restante do país, a partir do esforço conjunto do Governo e da sociedade, no auxílio e suporte aos agricultores familiares.

Com base na meta atual, até o final do ano de 2014, é possível que o Programa alcance $90 \%$ das contratações previstas nas regiões Sul, Sudeste, Norte e Centro-Oeste, porém, no Nordeste, esse número pode chegar a apenas $40 \%$ do objetivo total.

Em relação às limitações de estudo, identificou-se que: (1) o PNHR ainda está em fase de execução até o final do ano de 2014, o que não permite a obtenção de dados conclusivos; (2) a ausência de uma pesquisa regionalizada para verificar in loco os problemas ocorridos na implantação e contratação do PNHR em todas as regiões do país.

A partir dessas limitações, sugerem-se pesquisas futuras para verificar se o Programa atingiu o número de contratações estipulado e se essas contratações colaboraram para reduzir o déficit habitacional rural no país, além de entender quais medidas foram adotadas para minimizar o déficit habitacional rural na região Nordeste.

\section{REFERÊNCIAS}

ALBUQUERQUE, Maria do Carmo (Org.). Participação popular em políticas públicas: espaço de construção da democracia brasileira. São Paulo: Instituto Pólis, 2006.

CARVALHO, Maria do Carmo Brant. Alguns apontamentos para o debate. In: RICO, Elizabeth de Melo; RAICHELIS, Raquel (Orgs.). Gestão Social - uma questão em debate. São Paulo: Educ/IEE/PUCSP, 1999. p. 19-29.

CERVO, Amado Luiz; BERVIAN, Alcino Pedro. Metodologia Científica. 4. ed. São Paulo: Makron Books, 1996.

CONSTITUIÇÃO DA REPÚBLICA FEDERATIVA DO BRASIL. Disponível em: <http://www.ifam. edu.br/portal/images/file/Constitui\%C3\%A7\%C3\%A30\%20Federal\%20atualizada\%20 at\%C3\%A9\%20a\%20EC\%2073\%20de\%206.06.13.pdf>. Acesso em: 30 ago. 2013.

COSTA, André Monteiro et al. Perfil das condições de habitação e relações com a saúde no Brasil. XXVIII Congresso Interamericano de Ingeniezzá Sanitaria y Ambiental. Cancun, México. 27- 31 out. 2002.

DECLARAÇÃO UNIVERSAL DOS DIREITOS HUMANOS. Disponível em: <http://portal. mj.gov.br/sedh/ct/legis_intern/ddh_bib_inter_universal.htm>. Acesso em: 30 out. 2013.

DOWBOR, Ladislau. Tendências da gestão social. Revista Saúde e sociedade. n. 8, p. 3-15, 1999.

FRANÇA FILHO, Genauto de Carvalho. Definindo Gestão Social. I Encontro Nacional de Pesquisadores em Gestão Social (I ENAPEGS) - Juazeiro do Norte, 23-25 maio 2007.

GODOY, Arilda Schmidt. Pesquisa qualitativa: tipos fundamentais. Revista de administração de empresas - RAE, São Paulo, v. 35, n. 3, p. 20-25, maio/jun., 1995. 
IBGE. INSTITUTO BRASILEIRO DE GEOGRAFIA E ESTATÍsTICA. Pesquisa Nacional por Amostra de Domicílios (Pnad). Rio de Janeiro, 2008.

LANNOY, Camilo Pablo de. O descompasso das políticas públicas para solução do déficit habitacional. Disponível em: <http://repositorio.unb.br/bitstream/10482/ 3626/1/2006_Camilo\%20Pablo\%20de\%20Lannoy.pdf>. 2006. Acesso em: 28 ago. 2013.

MAIA. Marilene. Gestão Social - Reconhecendo e construindo referenciais. Revista Virtual Textos \& Contextos, ano IV, n. 4, dez. 2005

MALHOTRA, Naresh. Pesquisa de marketing: uma orientação aplicada. 3. ed. Porto Alegre: Bookman, 2001.

MINISTÉRIO DAS CIDADES. Cadernos MCidades Habitação. Disponível em:<http://www. capacidades.gov.br/biblioteca/detalhar/id/127/titulo/Cadernos+MCidades+4+-+Politica+ Nacional+de+Habitacao>. 2004, Brasília. Acesso em: 28 ago. 2013.

NEVES, José Luis. Pesquisa qualitativa - Características, usos e possibilidades. Caderno de Pesquisa em Administração, São Paulo, v. 1, n. 3, 2 sem. 1996.

PEREIRA, Potyara A. P. A Assistência Social na perspectiva dos direitos. Crítica aos padrões dominantes de proteção aos pobres no Brasil. Brasília: Thesaurus, 1996

RAICHELIS, Raquel. Democratizar a gestão das políticas sociais - um desafio a ser enfrentado pela sociedade civil. In: MOTA, Ana Elizabete (Org.). Serviço Social e saúde: formação e trabalho profissional. 3. ed. São Paulo: Cortez, 2008.

RICHARDSON, Roberto Jarry. Pesquisa social: métodos e técnicas. São Paulo: Atlas, 1989.

ROVER, Oscar J.; MUNARINI, Paulo P. A política de habitação rural e o desenvolvimento da agricultura familiar. Revista Katal, v. 13, n. 2, p. 260-269, jul./dez. 2010.

SAMPAIO, Arlete. As políticas de desenvolvimento social no Brasil. Disponível em: <http://www.democraciasocialista.org.br/democraciasocialista/noticias/item?item id=360413 > . Acesso em: 28 ago. 2012.

SOUZA. Celina. Políticas Públicas: uma revisão da literatura. Sociologias, Porto Alegre, ano 8, n. 16, p. 20-45, jul./dez., 2006.

SINGER, Paul. Alternativas da gestão social diante da crise do trabalho. In: RICO, Elizabeth de Melo; RAICHELIS, Raquel (Orgs.). Gestão Social - uma questão em debate. São Paulo: Educ/IEE/PUCSP, 1999. p. 55-66.

VIEIRA, Valter Afonso. As tipologias, variações e características da pesquisa de marketing. Revista da FAE, Curitiba, v. 5, n. 1, p. 61-70, jan./abr. 2002. 